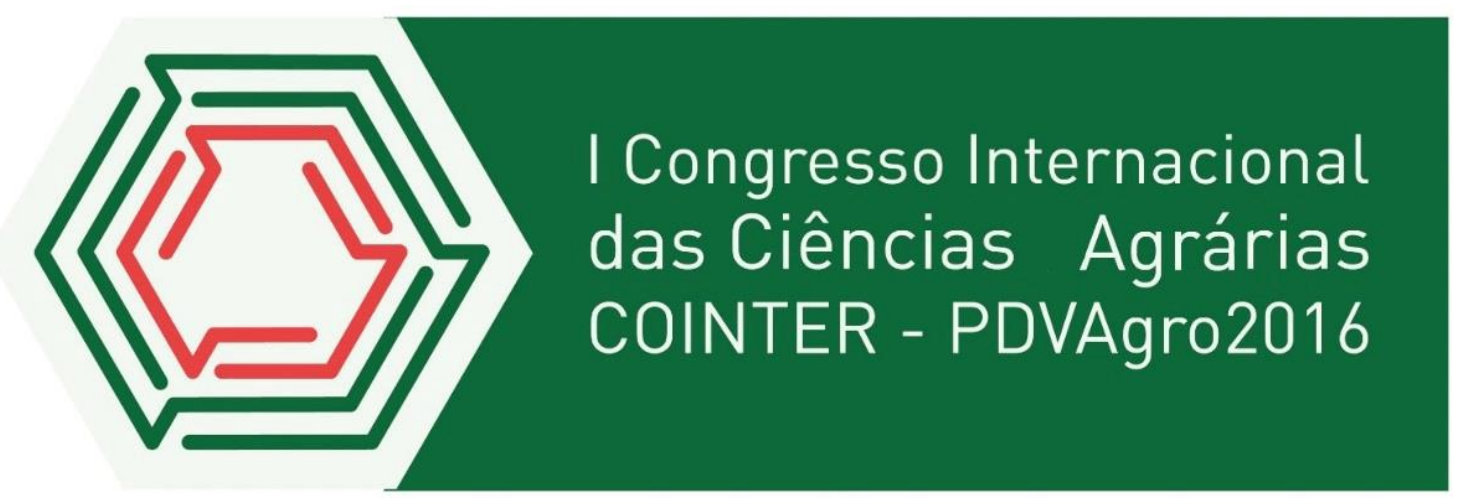

\title{
CRESCIMENTO E PRODUÇÃO DA CULTURA DO JERIMUM CABOCLO ORGÂNICO NO MUNICÍPIO DE CATOLÉ DO ROCHA/PB
}

\author{
Apresentação: Pôster
}

Elionária De Lima Figueredo ${ }^{1}$; William Fernandes Batista ${ }^{1}$; José Avelino De Queiroga Neto ${ }^{1}$; Ubiratan Matias De Queiroga Júnior ${ }^{1}$; Raimundo Andrade ${ }^{2}$

\footnotetext{
${ }^{1}$ Graduandos do Curso de Ciências Agrárias/DAE/UEPB, E-mail: elionarialima@ @otmail.com

${ }^{2}$ Prof. Doutor/Pesquisador DAE/CCHA/UEPB, E-mail: raimundoandrade@uepb.edu.br
}

\section{Introdução}

A família das cucurbitáceas é uma das mais importantes no domínio alimentício. As espécies do gênero cucúrbita foram domesticadas no Novo Mundo e cultivadas há milênios pelos povos Ameríndios. As abóboras fazem parte da alimentação da civilização Olmeca, depois incorporadas pelas civilizações Asteca, Inca e Maia (FERREIRA, 2007).

A produção de biofertilizantes é decorrente do processo de fermentação, ou seja, da atividade dos microorganismos na decomposição da matéria orgânica e complexação de nutrientes, o que pode ser obtido com a simples mistura de água e esterco fresco. (TIMM et al, 2004; SANTOS, 1992).

A adubação orgânica é importante para fertilização dos solos, tão grandes e tão variadas são os seus papéis. A matéria orgânica decompõe-se nos solos tropicais ou subtropicais com muita rapidez. A redução muito alta do teor de matéria orgânica do solo prejudica-o física, química e biologicamente, contribuindo para uma diminuição na produtividade (MALAVOLTA et al., 1997).

Diante o exposto, objetivou-se avaliar o desenvolvimento da cultura do jerimum caboclo em função de diferentes doses de biofertilizante e quantidades de húmus de minhocas em adubação orgânica de fundação. 


\section{Fundamentação Teórica}

O gênero Cucurbita é representado por cerca de cinco espécies cultivadas (LIRASAADE, 1995) destacando-se, entre elas, a abóbora (Cucurbita moschata). Juntamente com o pepino (Cucumis sativus), o melão (Cucumis melo), a melancia (Citrulus lanatus), o maxixe (Cucumis anguria), o jerimum (Cucurbita maxima) e a abobrinha ou abobrinha italiana (Cucurbita pepo), pertence à família das cucurbitáceas, é nativa das Américas e sua importância, relaciona-se, principalmente, ao valor alimentício e versatilidade culinária dos frutos.

Nos últimos anos, a valorização da abóbora tem sido crescente e importante para a diversificação da propriedade familiar e como alimento que contribui para a nutrição e saúde da população, desde que possui alto teor de antioxidantes, principalmente carotenóides pró-vitamina A (AMAYA, 1997).

A agricultura orgânica é praticada em todo o mundo, destacando-se a Europa, com 175 mil propriedades orgânicas, com uma área de 5,1 milhões de hectares, e a América Central, com 75 mil propriedades orgânicas, com uma área de 4,7 milhões de hectares (YUSSEFI, 2003).

De acordo com Santos (2001), biofertilizante é a designação dada ao efluente líquido obtido da fermentação metanogênica da matéria orgânica e água; enquanto Alves et al. (2001), o definem como resíduo final da fermentação de compostos orgânicos que contêm células vivas ou latentes de microrganismos (bactérias, leveduras, algas e fungos filamentosos) e por seus metabólicos, além de relatos organominerais.

\section{Metodologia}

A pesquisa foi realizada em condições de campo, no Centro de Ciências Humanas e Agrárias, pertencente à Universidade Estadual da Paraíba, distando 02 km da sede do município de Catolé do Rocha/PB, cujo as coordenadas geográficas são $\left(6^{0} 20^{\prime} 38^{\prime \prime}\right.$ de latitude sul; $37^{0} 44^{\prime} 48^{\prime \prime}$ a oeste do meridiano de Greenwich com uma altitude de 275 m acima do nível do mar, o referido município está situado na região semiárida do Nordeste brasileiro, no Noroeste do Estado da Paraíba.

O delineamento experimental adotado foi em blocos casualizados (DBC), com quatro repetições e 128 plantas úteis, em esquema fatorial de 4 x 4 totalizando 16 tratamentos com 2 plantas por unidade experimentais. Os tratamentos foram referentes a quatro doses de biofertilizante via solo $\left[\left(\mathrm{D}_{1}=0,0 \quad(\mathrm{~mL} / \mathrm{planta} / \mathrm{vez}) ; \mathrm{D}_{2}=50\right.\right.$ $(\mathrm{mL} /$ planta/vez $) ; \mathrm{D}_{3}=100(\mathrm{~mL} /$ planta/vez $) ; \mathrm{D}_{4}=150(\mathrm{ml} /$ planta/vez $\left.\left.)\right)\right]$, e quatro 
quantidades de húmus de minhocas $\left(\mathrm{Q}_{1}=0,0 ; \mathrm{Q}_{2}=500 ; \mathrm{Q}_{3}=1000\right.$ e $\left.\mathrm{S}_{4}=1500 \mathrm{~g} / \mathrm{cova}\right)$ no crescimento e produção de plantas de Jerimum caboclo orgânico.

\section{Resultados e Discussão}

O comportamento do comprimento do ramo principal de plantas de jerimum caboclo orgânico, em relação às doses de biofertilizante, teve um comportamento linear decrescente (Figura 01). Verificou-se que o comprimento do ramo principal de jerimunzeiro foi decrescendo de forma significativa com o aumento das doses de biofertilizante, tendo havido uma diminuição de $-0,0015 \mathrm{~cm}$ do comprimento do ramo principal por aumento unitário das doses de biofertilizante em plantas de jerimum, atingindo, no nível mínimo ( $\mathrm{D}_{4}=150 \mathrm{ml} /$ planta/vez. Conforme (Figura 02), A equação de regressão ajustada aos dados experimentais do comprimento do ramo principal, em relação às quantidades de húmus de minhocas, teve um comportamento linear, com coeficiente de determinação de 0,99 , tendo havido aumento linear dessa variável com o incremento da aplicação de húmus, observando-se um aumento de 0,0006 $\mathrm{cm}$ por aumento unitário da quantidade de húmus, provavelmente, em conseqüência da melhoria das características físicas, químicas e biológicas do solo, elevando o potencial de fertilidade, o que resulta em plantas nutricialmente mais equilibradas (OLIVEIRA e ESTRELA, 1984; SANTOS e SAMPAIO, 1993; SANTOS e AKIBA, 1996), houve efeito significativo, apresentando comportamento linear crescente com um aumento de 0,006 por aumento unitário das doses de biofertilizante sobre o comprimento do ramo principal de jerimum caboclo.

Figura 01. Doses de biofertilizante na cultura do jerimum caboclo.

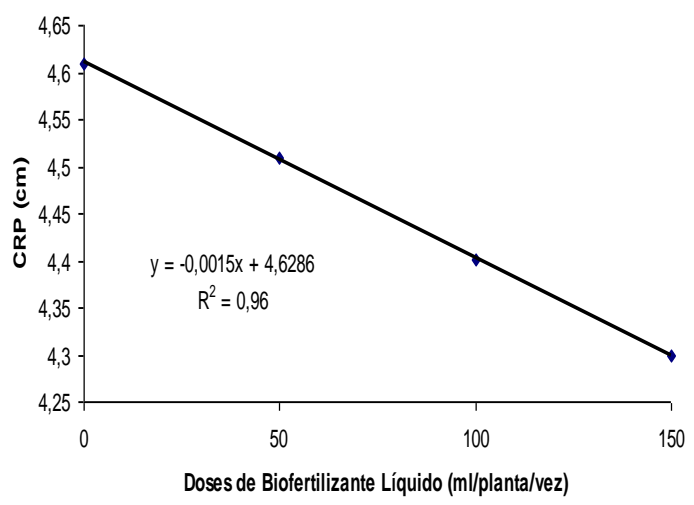

O número de frutos de jerimum caboclo, em relação às dosagens de biofertilizante, teve um comportamento similar para ambos os tratamentos não 
apresentando significância estatística (Figura 03), também não houve efeito significativo para a quantidade de húmus de minhocas, apresentando semelhança no comportamento dos tratamentos estudados (Figura 04).

Figura 03. Doses de biofertilizante na cultura jerimum caboclo orgânico.

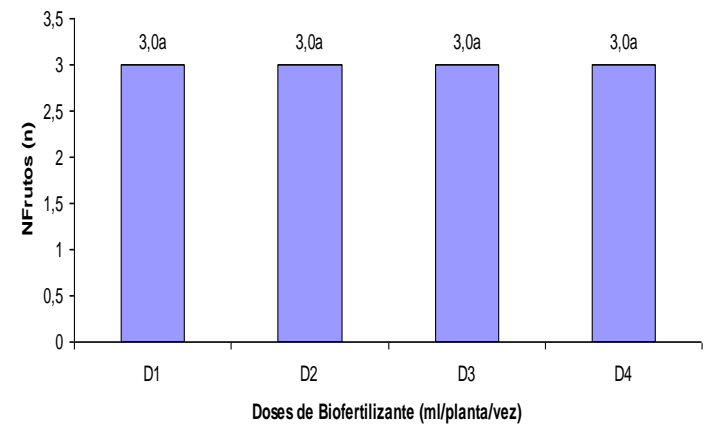

Figura 04. Quantidade de húmus na cultura do jerimum.

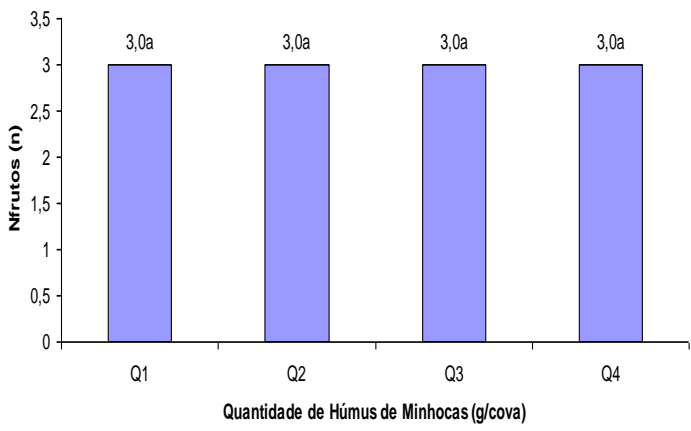

\section{Conclusões}

A dose $150 \mathrm{ml} / \mathrm{planta} / \mathrm{vez}$ de biofertilizante obteve o valor mínimo de 4,30 m no comprimento do ramo principal;

O valor máximo da quantidade de húmus foi de 1500 (g/cova) para o comprimento do ramo principal do jerimunzeiro de 4,93 m;

Para as dosagens de biofertilizante e quantidade de húmus de minhocas não apresentaram efeito significativo nos diferentes tratamentos estudados em função do número de frutos por planta;

\section{Referências}

AMAYA, D. R. Carotenoids and Food Preparation: The Retention of Provitamin A Carotenoids in Prepared, Processed, and Stored Foods. Campinas: UNICAMP, 1997. 93 p.

ALVES, S. B.; MEDEIROS, M. B.; TAMAI, M. A.; LOPES, R. B. Trofobiose e microrganismos na proteção de plantas: Biofertilizantes e entomopatógenos na citricultura orgânica. Biotecnologia Ciência \& Desenvolvimento, n.21, p.16-21, 2001.

FERREIRA, M. A. J. F. Abóboras, morangas e abobrinhas: estratéias para coleta, conservação e uso. 2007. Artigo em hpertexto. Disponível em: $<$ http:://www.infobibos.com/artigos/2007.

LIRA-SAADE, R. L. Estudios taxonomicos y ecogeograficos de las cucurbitaceae latinoamericanas de importancia económica. Rome: IPGRI, 1995. 281 p. (IPGRI. Systematic and Ecogeographic Studies on Crop Genepools, 9). 
MALAVOLTA, E.; VITTI, G. C.; OLIVEIRA, S. A. Avaliação do estado nutricional das plantas: princípios e aplicações. Piracicaba: POTAFOS, 1997. 201p.

OLIVEIRA, I.P.; ESTRELA, M. F. C. Biofertilizante do animal: potencial e uso. In: ENCONTRO DE TÉCNICOS EM BIDIESTORES DO SISTEMA EMBRAPA, 1993. Goiânia, Resumos... Brasília: EMBBRAPA, 1984. p. 16.

SANTOS, A. C. V.; AKIBA, F. Biofertilizante líquido: uso correto na agricultura alternativa. Serapédica:: Imprensa Universitária, 1996. 35p.

SANTOS, A. C. V. dos. Biofertilizante líquido, o defensivo da natureza. Niteroi: EMATER - Rio, 1992. 16 p. (Agropecuaria fluminense, 8).

SANTOS, A. C. V.; SAMPAIO, H. N. Efeito do biofertilizante líquido obtido a partir da fermentação anaeróbia do esterco bovino, no controle de insetos prejudiciais à lavoura de citros e seus inimigos naturais. In: SEMINÁRIO BIENAL DE PESQUISA, 1993, Resumos...Seropédica: UFRJ, 1993

TIMM, P. J.; GOMES, J. C. C.; MORSELLI, T. B. Insumos para agroecologia: Pesquisa em vermicompostagem e producao de biofertilizantes liquidos. Revista Ciência \& Ambiente, julho/dezembro, 2004. Universidade federal de santa Maria $29^{\circ}$ publicacao.

YUSSEFI, M. Developanent and state of organic agriculture word-wide. In: YUSSEFI, M. WILLER, H. The word of organic agriculture, 2003. Statistics and future 